\section{Evolution of Colonial Territories}

THE debate on March 16 in the House of Commons on Colonial affairs may well come to be regarded as marking the beginning of a new phase in the handling of Colonial affairs the phase that must follow and give substance to the accepted aspirations for the advance of the Colonial peoples to economic security, social well-being and ultimate partnership as responsible communities in the British Commonwealth. It was a first discussion of concrete but comprehensive plans for the development of one of the main regional entities into which the consideration of Colonial development will have, in increasing measure, to be grouped. The Stockdale Report, the proposals for a new constitution in Jamaica and the work of the Anglo-American Caribbean Commission which provided the substance of Colonel Stanley's speech, touched on every aspect of the development of the West. Indies and raised the concrete issues involved in the next stages of advance. The Colonial Secretary himself emphasized the need to start with practical solutions of concrete problems. The proposals for the Jamaican constitution, published as a White Paper, attempt to give expression to the largest possible consensus of local opinion. Thus a bi-cameral system has been recommended, despite official demands for great simplicity, on the ground that a great deal more depends upon the spirit in which any constitution is going to be worked than upon the actual machinery that is devised. The proposal is seen as only a stage on the way. The paramount aim is declared to be to ensure further advances towards complete responsible government.

The Stockdale Report, in the same way, concentrates on the most essential needs and the recommendation of immediately practical remedies without losing sight of the long-term problems. Here the Colonial Secretary wisely emphasized the danger of reaction from recent conditions of insecurity in the export trade to too great a measure of self-sufficiency, which would condemn the West Indies and many other Colonial areas to an intolerably low standard of living. Here again, the achievements and the programme of the Anglo-American Commission constitute an immediate and practical response. By providing an organization which will bring the British West Indies and the rest of the Caribbean area together to find common solutions for their problems, the Commission is an instrument for the first, modest but indispensable, steps necessary to fit them into a prosperous world economy. All this is evidence of an enlightened and purposeful empiricism long overdue in the approach to Colonial problems.

\section{Education and the Colonies}

Prof. A. V. Hur, in the debate on Colonial affairs in the House of Commons, has given his powerful aid to recent pleas for the active support and co-operation of the universities of the British Empire in the advance of Colonial education. He recalls the opportunity for their active participation in the training of the body of teachers and scientific and professional men that the Colonial peoples so greatly need, and must provide as rapidly as possible from their own ranks $\mathrm{He}$ suggests not only taking a mission-with a harmonium rather than a big drum -around the universities to enlist their active contribution, but also the establishment of a central organization of some kind to wateh over the needs of the higher education of Colonial peoples and to bring their needs and the opportunities these offer continually to the notice of schools, universities and learned societies at home.

There can be little doubt that both the universities and the Colonies would derive great mutual benefit from the closer contacts that would follow from an increasing flow of students from the Colonies to Great Britain and of visiting teachers, lecturers, educational advisers and examiners from the univer. sities to every part of the Colonial Empire. Moreover, Colonial development and welfare, as Prof. Hill declared, provide some of the grand adventures of our time. They constitute a creative task of social transformation. The initiative, energy and enthusiasm of many able young men and women in our schools and universities can be enlisted for the task of helping at the birth of these new societies. The immediate need is the widest appreciation of the needs and opportunities, and practical machinery which can operate without delay when the War is won.

\section{Post-War Air Transport}

THe debate upon post-war air transport in the House of Lords on March 11 disclosed several points of a technical nature. Viscount Cranborne said that it is the Government's wish to allot spheres of influence by international collaboration, and to avoid the cut-throat competition between air lines that have made it necessary in the past to grant subsidies in order to keep the services running in a manner worthy of the nation. The question of obtaining experience in air transport with the most modern aircraft, engines, and equipment is to be dealt with by the creation of an Air Transport Command within the R.A.F. This command will deal primarily with transport of materials and men, and its needs will bring parts of the industry into that sphere of design and production. Thus at the end of the War an organization should be in existence that can be changed over to civil air transport with the minimum of dislocation. It has since been announced that Air Chief Marshal Sir F. W. Bowhill, at present commanding officer of the R.A.F. Ferry Command, is to be in charge of this new section. Attention was also directed to the fact that a welldeveloped air transport service would be a valuable auxiliary to an invasion force operating on the European continent. Other suggestions were that a. Ministry of Air Transport should be created immediately, to make plans for the future based on its present-day experience, and that the shipping companies might be asked to run air services, auxiliary to their ships, allotting each item of traffic to that class of transport most suited to its requirements.

\section{Air Estimates in the House of Commons}

Sir Archibald SrNclate, Secretary of State for Air, discussing the Air Estimates in the House of Commons on March 11, mentioned several points of technical interest in recent R.A.F. development. During the past year, it has been found possible both to raise the standard of skill demanded and lengthen the period of training given in the R.A.F.; this at a time when it is known that both have been reduced in the enemy organization. One concrete result has been that the number of flying accidents during the past year was 20 per cent less than in the previous year. A very great expansion of training facilities has taken place, a joint Empire Air Training agreement being now in operation in the United Kingdom, 
Canada, Australia, and New Zealand. Expansion and improvement has taken place in the Air-Sea Rescue Service operating wherever the Allied air services are called upon to fly across the sea. An interesting variant of this, organized on similar lines, is the African desert rescue service, which has already saved about a hundred lives.

Another innovation is the introduction of a Commando Servicing Unit. Skilled mechanics, armed and trained to fight when necessary, are able to repair damaged aircraft under conditions that would normally mean their abandonment, and a very great saving in equipment has resulted. Tribute was also paid to the R.A.F. regiment, which has constantly been in the van of the advancing infantry, and has been able to re-condition enemy airfields even under fire. The effect of our bombing raids on Germany and the occupied countries goes far beyond the actual hold-up in the production of war material. Damage to transport systems and related workshops disorganizes the even flow of supplies to works, and delays the transport of troops to areas where they are required. The materials and labour necessary for the repair of damaged buildings also has to be diverted from war production.

\section{Sir Bennett Melvill Jones, C.B.E., F.R.S.}

Sir Bennett Melvill Jones, whose appointment to succeed Sir Henry Tizard as chairman of the Aeronautical Research Committee has been announced, has had a long ànd distinguished connexion with the scientific side of aeronautics. While his interests have ranged over almost the entire field of the subject, his name is more particularly associated with the elucidation of the problems arising out of the performance of aircraft. His work has resulted in a steady increase in the eiticiency of the flying machine as a whole, and this, particularly when devoted to raising the speed of flight, has set problems in stability and control that have called for complex and systematic investigation both in the laboratory and in actual flight. Following his student days at Cambridge he took up aeronautics at the National Physical Laboratory, Teddington, and so far back as 1912 contributed a paper to the old Advisory Committee for Aeronautics on the properties of aerofoils. A paper on the stability of kite balloons (1915) was another contribution of his that laid the foundation of the systematic study of stability in flight. He then spent a period with Messrs. Armstrong Whitworth on the development of rigid airships, and followed this by work at the Royal Aircraft Establishment, Farnborough, on flight research. During the War of 1914-i8 he was a member of the Experiment and Research Department of the newly constituted Air Board, and took an active part in the development of aerial warfare, particularly aerial gunnery, principally at the Experimental Station at Martlesham Heath.

Later, Melvill Jones was appointed Francis Mond professor of aeronautics in the University of Cambridge, a post which he still holds, and also became a member of the Aeronautical Research Committee. During that period he has contributed much to the development of those outlooks on aeronautics which he has made his own. He has been able to combine his theoretical work at the University with actual full-scale flying experiment at the R.A.F. station at Duxford. One of his most noted achievements during that period was to present a conception of the ideal streamlined aeroplane, suggesting general rules for its design that quickly received universal acceptance. During the present War he has been principally concerned with the development of fighting technique. He was elected a fellow of the Royal Society in 1939 and received his knighthood in 1942 .

\section{Royal Astronomical Society Gold Medallist}

As already announced, the Gold Medal of the Royal Astronomical Society has been awarded to Dr. H. Spencer Jones, Astronomer Royal, for his determination of the solar parallax from observations of the minor planet Eros, made at the very favour. able opposition of 1931. The solar parallax is a fundamental unit and is the astronomer's disguise for the principal astronomical unit of distance, namely, the mean distance of the earth from the sun. Dr. Spencer Jones' result for the solar parallax (v. Mon. Not. Roy. Ast. Soc., 101, 356; 1941) is $8 \cdot 790^{\prime \prime} \pm 0.001^{\prime \prime}$ and the corresponding mean distance of the earth from the sun is $93,003,000$ miles ; in each case the accuracy is of the order of 1 part in 10,000 . Such an achievement is remarkable, and the Society's award will be acclaimed by astronomers all over the world as an honour deservedly bestowed and brilliantly earned.

The actual observations of Eros, made photographically at about a score of observatories, are represented by nearly three thousand plates; in addition, the positions of several hundreds of primary reference stars and nearly six thousand fainter secondary stars had to be determined. The successful planning of an international campaign of this magnitude was, in itself, no mean feat. The discussion of the immense amount of observational material secured has evidently been thorough, and the Astronomer Royal appears to have overlooked no possible source of error. The Eros observations also provide means of determining accurately the moon's mass and the constant of nutation: the value of the latter is found to be inconsistent with the value usually accepted, and the Astronomer Royal's next activity would seem to be the resolution of this discrepancy.

\section{A New Method of Etching on Metals}

A NEW electrolytic process of etching on metals makes use of a standard waxed-paper stencil such as is used in a duplicating machine, on which is cut the required design. This is placed between the metal article, which forms the anode, and an absorbent pad containing the etching reagent, which is connected to the cathode of a 15 -volt D.C. circuit. The apparatus consists of a unit comprising the transformer, rectifier and output controller, giving a 15-volt D.C. supply from the 200/230-volt A.C. mains. When etching stainless materials, each stencil is good for at least fifteen etchings, or for about ten with less resistant alloys. The normal depth of attack is about 0.0005 in., and curved and irregular articles can be treated. The process is adapted to the marking of tools, plates, etc. The equipment is obtainable from Messrs. Griffin and Tatlock, Ltd., Kemble Street, Kingsway, London, W.C.2.

\section{Training of Civil Servants}

THE Chancellor of the Exchequer has announced that he has set up the following committee to consider the training of Civil servants: The Financial Secretary to the Treasury (Mr. Assheton), chairman; Sir Harold Hartley, vice-president, London Midland 